\title{
The Way to Resist Moisture Damage and Rutting In Asphalt Mixture in Bangladesh by the Application of Hydrated Lime
}

\author{
Sonia Rahman ${ }^{1}$ \\ ${ }^{I}$ (Civil Engineering, Bangladesh University of Engineering and Technology (BUET),Bangladesh)
}

\begin{abstract}
In Bangladesh, road way condition is very severe. Though the number of roads are less than what is required, again damages in road surface, specially in rainy season reduce the utility of these roads.Main aim of our paper is to improve the performance of asphalt pavement by using hydrated lime and determine the improvement of it to reduce the economic loss of our country.

Moisture damage can manifest in the hot mix asphalt pavements in forms of stripping and/or softening of asphalt. It results in loss of stability, bearing capacity failure and rutting of asphalt pavement. One of the common anti-stripping additives, hydrated lime, is considered to improve the properties of asphalt mixture in resisting moisture damage. The lime application process can be introduced to asphalt mixture by either adding dry hydrated lime to wet aggregates or adding lime slurry to dry aggregates. This study evaluates the laboratory performance-based properties of asphalt mixtures using two different lime application processes as well as to compare between hydrated lime-modified and polymer-modified asphalt mixture. Results indicated adding hydrated lime to asphalt binder is a cost effective method to improve performance of asphalt mixture in moisture damage and rutting resistance in Bangladesh. .
\end{abstract}

Keywords: Anti-stripping, Economic Loss, Hydrated lime, Improvement .Moisture damage.

\section{Introduction}

Moisture damage in the hot mix asphalt pavement is considered as one of major pavement deteriorations in Bangladesh, located in the tropical region with a substantial rainfall. The moisture damage causes loss of adhesion (e.g. loss of bonding between asphalt binder and aggregate), and adversely affect the strength of the asphalt mixture dramatically (Taylor and Khosla, 1983). For a high-volume road, the moisture damage can also cause the premature pavement distresses such as rutting and raveling on the pavement surface. The anti-stripping additives are widely employed to enhance the moisture damage resistance in asphalt mixture. Two common types of additives are the liquid anti-stripping additive and the hydrated lime. The liquid antistripping additive is typically applied directly to the asphalt binder, while the hydrated lime is applied to the aggregate. Lee and Nicholas (1954) indicated that the application of anti-stripping additive to the aggregate is more efficient than that to the asphalt binder. However, adding additives directly to asphalt binder is more economical (Lee and Nicholas, 1954). Because of the unpleasant odor of the liquid anti- stripping additive, and substantial amount of hydrated lime produced, the use of hydrated lime is more desirable to resolve moisture damage problem in Bangladesh.

\section{Objective}

Several studies showed the beneficial application of hydrated lime in the asphalt mixture to improve the moisture susceptibility (Plancher et al., 1977; Hicks, 1991; Little and Epps, 1953; Aschenbrener, 2002; Sebaaly, 2003; Bari and Witczak, 2005). However, most studies were conducted using the lime application process either by adding dry hydrated lime to wet aggregates or by adding lime slurry to dry aggregates (Epps $e t$ al., 2003). The performance- based properties of the hydrated lime modified asphalt mixtures by both processes were evaluated in this study. The properties of asphalt mixture prepared by adding hydrated lime to aggregates (dry mixing process) were compared with those prepared by adding hydrated lime to asphalt binder (wet mixing process). The optimum proportion of hydrated lime used in both processes were determined and selected according to the performance of asphalt mixtures and the cost-effectiveness

\section{Materials and Methods:}

Wet and dry mixing processes of hydrated lime application were used in the study. In the wet mixing process (as known as wet hydrated lime or WHL), the hydrated lime, was applied directly to the original asphalt binder $\mathrm{AC} 60 / 70$ at the mixing temperature of $145^{\circ} \mathrm{C}$. This temperature was used to obtain a homogenous mixture of asphalt binder and hydrated lime. The properties of hydrated lime used are summarized in Table 1. The Marshall mix design method (ASTM D3515) was selected in preparation of the asphalt mixture specimens because of widely adoption in Bangladesh. The hydrated lime used in the wet process was $10 \%$ and $20 \%$ by weight of asphalt binder. The 19-mm nominal maximum limestone aggregate was used to produce the asphalt 
The Way to Resist Moisture Damage and Rutting In Asphalt Mixture in Bangladesh by the Application mixture specimens in accordance with ASTM D3515.

Table 1: Properties of hydrated lime

\begin{tabular}{|l|l|l|}
\hline Item Analysis & Test Method & Measured Value \\
\hline Available $\mathrm{CaO}$ & ASTM C-25 & $72.58 \%$ \\
\hline Purity of $\mathrm{Ca}(\mathrm{OH}) 2$ & ASTM C-25 & $95.80 \%$ \\
\hline Moisture Content & ISO 787/1 & $0.19 \%$ \\
\hline Residue on \#170mesh & Wet sieve & $0.70 \%$ \\
\hline $\mathrm{pH}$ & $5 \%$ in DW & 12.25 \\
\hline
\end{tabular}

In the dry process (as known as dry hydrated lime or DHL), the hydrated lime was primarily added to the dry aggregate prior to mixing with the original asphalt binder. The hydrated lime used in the dry process was $0.5 \%$, and $1.5 \%$ by weight of dry aggregate. These proportions were selected because they have been used in practice in the hydrated lime application. Besides the two lime application processes, the polymer, another type of asphalt modifier, was used in the study. The original binder AC 60/70 was modified with styrene-butadienestyrene (SBS). This modification method is thereafter called the polymer-modified asphalt or PMA in this study.

\section{Experimental Program}

The experimental program consists of two main parts: asphalt binder tests and asphalt mixture tests. The asphalt binder tests include the rheological property test, and the creep and recovery test. The asphalt mixture tests include the indirect tensile strength test (AASHTO T283) and the loaded wheel tracking test. The experimental program and results for each test are described as the following.

\subsection{Asphalt Binder Test}

Four asphalt binders: original binder, polymer-modified binder, $10 \%$ and $20 \%$ wet hydrated lime (WHL) modified binders were tested using the Dynamic Shear Rheometer (DSR).

\subsubsection{Rheological Property Test}

The complex shear modulus $\left(\mathrm{G}^{*}\right)$ and phase angle $(\delta)$ of asphalt binders were measured at the specified temperature and loading frequency. $\mathrm{G}^{*}$ is a mechanical property that reflects the total resistance of the binder to deformation under a repetitive shearing stress. $G^{*}$ combines two major components: storage modulus $\left(\mathrm{G}^{\prime}\right)$ which is an elastic or recoverable component, and loss modulus $\left(\mathrm{G}^{\prime \prime}\right)$ which is a viscous or non-recoverable component. The elastic component reflects the amount of energy stored in the asphalt specimen in each testing cycle. The viscous component reflects the amount of energy lost in each testing cycle through permanent flow or deformation (Roberts et al., 1996). The test was conducted at loading frequency of $1 \mathrm{~Hz}$. Results of $\mathrm{G}^{*}, \mathrm{G}^{\prime}$, $\mathrm{G}^{\prime \prime}$, and $\delta$ are summarized in Table 2 .

Table $2: \mathrm{G}^{*}, \mathrm{G}^{\prime}, \mathrm{G}^{\prime \prime}$, and $\delta$ of asphalt binders tested under different temperatures

\begin{tabular}{|l|l|l|l|l|}
\hline Temperature $\left({ }^{\circ} \mathrm{C}\right)$ & $\mathrm{G}^{*}(\mathrm{~Pa})$ & $\mathrm{G}^{\prime}(\mathrm{Pa}) \mathrm{G}^{\prime \prime}(\mathrm{Pa})$ & $\mathrm{G}^{\prime \prime}(\mathrm{Pa})$ & $\delta(\mathrm{deg})$ \\
\hline Original Binder & 2530000 & 1290000 & 2180000 & 59.4 \\
\hline 22 & 560000 & 157000 & 537500 & 73.7 \\
\hline 28 & 7010 & 339 & 7000 & 87.2 \\
\hline 50 & 2310000 & 1410000 & 1835100 & 52.6 \\
\hline Polymer-Modified Asphalt (PMA) & 542000 & 64.2 \\
\hline 22 & 6020000 & 2620000 & 13800 & 68.1 \\
\hline 28 & 14900 & 5560 & & 52.0 \\
\hline 50 & \multicolumn{5}{|l|}{} & 66.8 \\
\hline $10 \%$ WHL Binder & 3130000 & 1930000 & 2470000 & 84.5 \\
\hline 22 & 716000 & 282000 & 658100 & 49.1 \\
\hline 28 & 10400 & 994 & 352 & 65.8 \\
\hline 50 & 4580000 & 3000000 & 831000 & 84.7 \\
\hline $20 \%$ WHL Binder & 911000 & 374000 & 12745 & \\
\hline 22 & 12800 & 1180 & & \\
\hline 28 &
\end{tabular}

\subsubsection{Creep and Recovery Test}

The resistance of asphalt binders to accumulation of permanent deformation (or strain) under a repetitive loading was measured using the creep and recovery test. The accumulated strain for each loading 
The Way to Resist Moisture Damage and Rutting In Asphalt Mixture in Bangladesh by the Application cycle, the rate of strain accumulation, and the viscous component of the creep stiffness (GV) are determined to evaluate the rutting resistance of asphalt binders. Table 3 summarizes the testing results of the original binder, the polymer-modified binder, and the original binder mixed with three varied amounts of hydrated lime. The creep and recovery test on these binders were conducted at $50^{\circ} \mathrm{C}$, which represents the high temperature encountered in the field.

Table 3: Effect of hydrated lime on rutting resistance of asphalt binders

\begin{tabular}{|l|l|l|l|}
\hline Binder & $\begin{array}{l}\text { Strain @ 50 cycles } \\
(\mathrm{mm} / \mathrm{mm})\end{array}$ & $\begin{array}{l}\text { Rate of strain } \\
\text { accumulation }\end{array}$ & $\begin{array}{l}\mathrm{GV} \text { at 1 sec. of loading } \\
(\mathrm{Pa})\end{array}$ \\
\hline Original & 5.33 & 0.923 & 9.56 \\
\hline PMA & 0.55 & 0.094 & 91.20 \\
\hline $10 \%$ WHL & 3.20 & 0.624 & 15.96 \\
\hline $20 \%$ WHL & 2.7 & 0.523 & 18.88 \\
\hline
\end{tabular}

* All tests were performed at the stress level of $100 \mathrm{~Pa}$.

\subsection{Asphalt Mixture Test}

A series of asphalt mixture tests including the indirect tensile strength (IDT) and the loaded wheel tracking test (LWT) were conducted on various types of asphalt mixture specimens: the original binder (control specimen) polymer-modified binder, $10 \%$ and $20 \%$ WHL modified binders, and $0.5 \%$ and $1.5 \%$ DHL

\subsubsection{Indirect Tensile Strength Test (IDT)}

The IDT test was conducted in accordance with AASHTO T283, a standard test method to measure the resistance of compacted bituminous mixtures to moisture induced damage. Six Marshall standard size specimens (102-mm diameter and 64-mm high) were compacted at the optimum binder content. These specimens were statically compacted for a loading duration of two minutes to attain $7 \%$ air voids.

Six compacted specimens were divided into two groups. The first three specimens were not subjected to any conditioning. The other three specimens were inundated, which resulting in approximately $55-80 \%$ degree of saturation. Afterwards, these specimens were conditioned in a water bath at $60^{\circ} \mathrm{C}$ for $24 \mathrm{hrs}$ following the AASHTO T283. Both unconditioned and conditioned specimens were kept in a water bath at $25^{\circ} \mathrm{C}$ for $1 \mathrm{hr}$ to allow thermal equilibration prior to testing.

During the test, every specimen was subjected to a loading rate of $51 \mathrm{~mm} / \mathrm{min}$ until failure. The compressive load was applied through two loading strips. The maximum indirect tensile force was recorded and the corresponding IDT strength of the asphalt mixture was determined. The tensile strength ratio (TSR), a ratio of the IDT strength of conditioned specimens to the IDT strength of unconditioned specimens, was calculated and used as a moisture susceptibility index of asphalt mixtures.

The calculated TSR of the original mixtures, polymer-modified mixtures, WHL-modified mixtures, and DHL-modified mixtures is presented in Table 4. Results indicated that the 20\% WHL and 1.5\% DHL modified mixtures show the highest TSR $(\sim 0.9)$. These percents of hydrated lime added in asphalt mixture can minimize the moisture susceptibility. The polymer-modified mixture however showed less influence on moisture damage resistance.

Table 4 :Tensile Strength Ratio (TSR) for modified and unmodified asphalt mixtures

\begin{tabular}{|l|l|}
\hline \% Hydrated Lime & TSR \\
\hline Original Mixtures & 0.84 \\
\hline 0 & \\
\hline Polymer-Modified Mixtures (PMA) & 0.81 \\
\hline 0 & \\
\hline WHL-Modified Mixtures & 0.85 \\
\hline 10 & 0.91 \\
\hline 20 & 0.81 \\
\hline WHL-Modified Mixtures & 0.90 \\
\hline 0.5 &
\end{tabular}

It should be noted that the aggregate used in this study is limestone, which is known as basic aggregate. Therefore, the original mixtures showed considerably high TSR value or less moisture sensitivity, as shown in Table 4. 
The Way to Resist Moisture Damage and Rutting In Asphalt Mixture in Bangladesh by the Application

\subsubsection{Loaded Wheel Tracking (LWT) Test}

The LWT test was conducted to measure the resistance of asphalt mixtures to rutting under the waterexposed condition. To evaluate the effect of hydrated lime on the rutting resistance as measured by the loaded wheel tracking test, three types of asphalt mixtures were tested. They include the original, polymer-modified, $20 \%$ WHL, and 1.5\% DHL asphalt mixtures. Note that the 20\% WHL and 1.5\% DHL were selected in the LWT test because they exhibit desirable performance in the moisture damage resistance and high stiffness in both wet and dry mixing processes.

As number of cycles increase, the rut depth or permanent deformation of specimen increases. Results indicated that the hydrated lime can improve the resistance of mixtures to rutting under the water-exposed condition. As shown in Table 5, the 1.5\% DHL specimen show higher rutting resistance than 20\% WHL specimen, however, no significant difference in the rate of permanent deformation was observed. In addition, the $1.5 \%$ DHL specimen has comparable rutting resistance with the polymer modified mixture specimen.

Table 5 :Average rut depth and rate of permanent deformation measured by the LWT test (with $36 \mathrm{~kg}$. loading at $\left.50^{\circ} \mathrm{C}\right)$

\begin{tabular}{|l|l|l|}
\hline Mixtures & Average Rut Depth $(\mathrm{mm})$ & $\begin{array}{l}\text { Rate of Permanent Deformation } \\
(\mu \mathrm{m} / \text { cycle })\end{array}$ \\
\hline Original & 8.22 & 0.5 \\
\hline PMA & 4.32 & 0.3 \\
\hline $20 \%$ WHL & 5.11 & 0.2 \\
\hline $1.5 \%$ DHL & 4.41 & 0.3 \\
\hline
\end{tabular}

\section{Conclusion and Recommendation}

Based on the analysis of data collected in this study, the summary of findings are as the following: 1.The rheological property test and the creep and recovery test conducted on the asphalt binders indicated significant changes in the performance of asphalt binder when the hydrated lime was used as asphalt modifiers. 2.Hydrated lime applied in asphalt binder increases both $G^{*} / \sin \delta$ and $G^{*} \sin \delta$, and increases the rutting resistance by having larger viscous component of the creep stiffness $(\mathrm{GV})$.

3.Polymer used in this study showed slightly decreases in both $\mathrm{G}^{*} / \sin \delta$ and $\mathrm{G}^{*} \sin \delta$ at intermediate temperature. Asphalt binder significantly increase $\mathrm{G}^{*} / \sin \delta$ and $\mathrm{G}^{*} \sin \delta$ at high temperature, and significantly increase in the rutting resistance component of the creep stiffness $(\mathrm{GV})$.

4.The overall performances of asphalt mixtures modified with hydrated lime are

more desirable than those of unmodified mixtures, especially for the mixtures adding $20 \%$ hydrated lime (by weight of asphalt) in binder prior to mixing with aggregate, and the mixtures prepared by applying $1.5 \%$ hydrated lime (by weight of aggregate) in dry aggregate prior to mixing with asphalt binder.

5.Although comparable overall performance, it is more economical to add $20 \%$ hydrated lime (by weight of asphalt) to binder prior to mixing with aggregate than applying $1.5 \%$ hydrated lime (by weight of aggregate) in dry aggregate prior to mixing with asphalt binder.

6.Besides the polymers, the hydrated lime can be considered as an alternative modifier to improve the properties of asphalt binders and mixtures. The hydrated lime can significantly improve both moisture damage and rutting resistance, while the polymer can significantly improve rutting resistance only.

7.The application of hydrated lime in asphalt binder is an effective and economical method to improve the performance of asphalt mixture to resist moisture damage and rutting.

\section{Acknowledgement}

Thanks to Almighty Allah for his unlimited mercifulness and blessing of whom all success are accomplished. I would like to express my deepest and sincerest gratitude to my supervisor Professor Dr. Md. Mizanur Rahman for his incessant guidance, spirited encouragement and constructive criticism at every stage of this study.

\section{Journal Papers:}

\section{References}

[1] Plancher, H., Dorrence, S.M., Petersen, J.C. Identification of Chemical Types in Asphalts Strongly Absorbed at the AsphaltAggregate Interface and Their Relative Displacement by Water, Journal of the Asphalt Paving Technologists, Vol. 46,1977, 151175 .

Books:

[2] Roberts, F.L., Kandhal, P.S., Brown, E.R., Lee, D.Y., and Kennedy, T.W. Hot mix asphalt materials, mixture design, and construction, (Second edition, NAPA,1996)

[3] Lee, A.R. and Nicholas, J.W. Adhesion in the Construction and Maintenance of Roads, Adhesion and Adhesives, Fundamentals and Practice, (Society of Chemical Industry, London,1989.) 


\section{Thesis:}

[4] Little, D.N. and Epps, J.A. Hydrated Lime in Hot-Mix Asphalt. Presentation Manual, FHWA-HI-93-032, FHWA, AASHTO, and National Lime Association, prepared for Chemical Lime Company, Fort Worth, Texas, 1993.

[5] Aschenbrener, T.B. Results of Survey on Moisture Damage of Hot-Mix Asphalt Pavements, Colorado Department of Transportation, Denver,2002.

\section{Research Board Paper}

[6] Taylor, M.A. and Khosla, N.P.Stripping of Asphalt Pavements: State of the Art, Transportation Research Record 911, Transportation Research Board, Washington, D.C ,1983.

[7] Hicks, R.G. NCHRP Synthesis of Highway Practice 175: Moisture Damage in Asphalt Concrete, Transportation Research Board, Washington, D.C.1991.

[8] Sebaaly, P.E., Hitti, E., and Weitzel, D. Effectiveness of Lime in Hot Mix Asphalt Pavements, Transportation Research Record 1832, Transportation Research Board, Washington, D.C. 2003.

[9] Bari, J. and Witczak, M.W. An Evaluation of the Effect of Lime Modification on Dynamic Modulus Stiffness of HMA for Use with the New NCHRP 1-37A M-E Pavement Design Guide Procedures, Transportation Research Record 1929, Transportation Research Board, Washington, D.C.2005.

[10] Epps, J., Berger, E., Anagnos, J.N. Treatments, Moisture Sensitivity of Asphalt Pavements, a National Seminar, Transportation Research Board,2003 